\title{
Aulas Laboratoriais de Geografia: Proposições para o Ensino de Graduação
}

\author{
Maria Eliza Miranda* \\ Departamento de Geografia da Faculdade de Filosofia, Letras e Ciências Humanas da Universidade de São Paulo \\ * Autora para correspondência: elizamir@usp.br
}

\begin{abstract}
RESUMO
A cultura científica acadêmica atualmente está enfrentando inúmeros desafios que envolvem, entre outros aspectos, a fragmentação do conhecimento e a diluição de sua essência, dificultando a aptidão natural, a propensão e o potencial próprios dos ingressantes na universidade para contextualizar e englobar o conhecimento a fim de apreender sua complexidade. A metodologia das aulas laboratoriais visa a articular o campo de conhecimento específico, no caso aqui, a Geografia, e o conhecimento geral psicológico e pedagógico, necessários à atuação docente e discente no ambiente acadêmico, desenvolvendo habilidades de reflexão, de pesquisa e de utilização de tecnologias e diversas linguagens no ensino e aprendizagem em nível de graduação. As aulas laboratoriais se configuram como um exercício de independência intelectual e de trabalho colaborativo, que resultam em diferentes entendimentos acerca da natureza do papel docente e discente na universidade, que valoriza a vivência acadêmica do aluno e mobiliza a aprendizagem das relações entre teoria-prática-plano, favorecendo a formação de um sujeito ativo (capaz de fazer escolhas), dialógico na relação com os outros e crítico em relação às tendências que valorizam o individualismo e a efemeridade da vida social e política.
\end{abstract}

Palavras-chave: Formação Intelectual; Geografia; Metodologia Ativa; Ensino de Graduação.

\begin{abstract}
The academic culture is currently facing numerous challenges involving, among other things, the fragmentation of knowledge and the dilution of its essence, making harder the natural aptitude, propensity and own potential of university students to contextualize and embrace the knowledge in order to understand its complexity. The methodology of "laboratory class" aims to articulate the specific field of knowledge, in this case, Geography, and the pedagogical general knowledge necessary for teaching and student performance in academic environment, developing thinking skills, research and use of technology and various languages in teaching and learning at the undergraduate level. Laboratory classes are configured as an exercise of intellectual independence and collaborative work, which result in different understandings about the nature of teaching and student paper at the university that values academic experience of students and mobilizes the learning of the relationship between theory-practice-plan, favoring the formation of an active subject, capable of making choices, dialogic in relation to others and critical of the tendencies that value individualism and the frailty of social and political life.
\end{abstract}

Keywords: Intellectual Formation; Geography; Active Methodology; Teaching; Undergraduate.

É possível atualmente se considerar que a maior inovação na Educação é a própria possibilidade de ensinar e aprender a pensar. Castells já alertava em sua trilogia sobre a "Era da Informação" que "até aqui, foi necessário muito conhecimento para construir tecnologias, mas daqui para frente precisaremos de muita tecnologia para construir novos conhecimentos" (1999, pp. 77-81). E, salvo melhor juízo, nessa ideia estão contidos todos os dilemas que enfrentamos hoje nas diversas esferas da vida social e, principalmente, na Educação.
O alcance das tecnologias e das ciências até aqui produzidas possibilita ao Ensino Superior reinventar significados e sentidos do conhecimento da humanidade, ensinando também a moral e a ética que presidem a universalidade e a singularidade da humanidade.

É possível a Educação transmitir às novas gerações os valores sociais, culturais, políticos e econômicos do conhecimento e da tecnologia da humanidade e, simultaneamente, estimular o 
cultivo do pensamento utópico (crítico), pois a emancipação, a liberdade, a felicidade e a segurança individual dependem cada vez mais da existência social e política, e podem ser pensadas no presente tanto ou mais do que já o foram no passado.

São razões sociais e políticas, em última instância, e não econômicas e técnicas, portanto, que indicam a necessidade de repensar e formular um projeto de Educação, a partir do qual toda individualidade e subjetividade possam conduzir sua ação no sentido de uma sociedade mais democrática e livre com maior justiça social, fundamentada na universalidade do humanismo como utopia ainda a ser alcançada (WOLFF, 2012).

Temos trabalhado na perspectiva de que o Ensino Superior pode alimentar essa utopia para o mundo em que vivemos, pois sem utopia o Ensino Superior perde o sentido e permanece apenas como retórica ou técnica. A necessidade e a possibilidade de pensá-lo ao mesmo tempo como vivência da passagem para um devir apoiam que direcionemos nossa crítica para o passado e o presente, sem o que não suportaríamos viver.

No tempo-espaço atual, nunca vivido anteriormente pela humanidade, não há futuro porque tem sido o mundo do aqui e agora, on-line. E o Ensino Superior pode ser pensado como uma possibilidade, nem sempre visível como tal no tempo-espaço deste mundo, que indica a necessidade de produzir outros horizontes possíveis nele.

O Ensino Superior também contém a própria tensão que ocorre no tempo-espaço on-line. Sobre ele pairam todas as contradições e limites, e também as possibilidades do passado, do presente e do futuro.

O título que adotamos neste artigo pode sugerir que estamos lidando com equipamentos e aparelhos que servem às experiências, testes ou materiais específicos em local apropriado para tal. Entretanto, não é bem disso que se trata. $\mathrm{O}$ principal elemento envolvido é a própria propensão e o incomensurável potencial para aprender que o ser humano possui se considerarmos o nível atual de conhecimentos interdisciplinares que se acumulam acerca das relações entre aprendizagem e o funcionamento do cérebro humano.
Na verdade, a expressão "aulas laboratoriais" de nosso título é uma metáfora que procura expressar a necessidade da aprendizagem da transitoriedade e relatividade da verdade científica no Ensino Superior de graduação no Brasil. Buscamos caracterizar uma prática aberta e voltada ao início da graduação, visando a apoiar a transição de alunos ingressantes na universidade para a cultura acadêmica e científica. Podemos dizer que as aulas laboratoriais compreendem curtos seminários que caracterizam exposições, problematizações, discussões e reflexões a respeito de temas, assuntos e conteúdos específicos, teóricos e aplicados, de nível universitário.

A cultura acadêmica atualmente está enfrentando inúmeros desafios que envolvem, entre outros aspectos, a fragmentação do conhecimento e a diluição de sua essência, dificultando a aptidão natural, a propensão e o potencial próprios dos ingressantes na universidade para contextualizar e englobar o conhecimento a fim de apreender sua complexidade.

Morin caracteriza largos aspectos deste desafio cultural quando afirma que

[...] A grande separação entre a cultura das humanidades e a cultura científica, iniciada no século passado e agravada neste século $\mathrm{XX}$, desencadeia sérias consequências para ambas. A cultura humanística é uma cultura genérica que, pela via da filosofia, do ensaio, do romance, alimenta a inteligência geral, enfrenta as grandes interrogações humanas, estimula a reflexão sobre o saber e favorece a integração pessoal dos conhecimentos. A cultura científica, bem diferente por natureza, separa as áreas do conhecimento; acarreta admiráveis descobertas, teorias geniais, mas não uma reflexão sobre o destino humano e sobre o futuro da própria ciência. A cultura das humanidades tende a se tornar um moinho despossuído do grão das conquistas científicas sobre o mundo e sobre a vida, que deveria alimentar suas grandes interrogações; a segunda, privada da reflexão sobre os problemas gerais e globais, torna-se incapaz de pensar sobre si mesma e de pensar os problemas sociais e humanos que coloca. [...] O mundo técnico e científico vê na cultura das humanidades apenas 
uma espécie de ornamento ou luxo estético [...], isto é, a inteligência geral que a mente humana aplica aos casos particulares. O mundo das humanidades vê na ciência apenas um amontoado de saberes abstratos ou ameaçadores. [...] (2008, pp. 17 e 18, grifos nossos).

A metodologia das aulas laboratoriais visa a articular o campo de conhecimento específico - no caso aqui, a Geografia -, o conhecimento geral psicológico e pedagógico - necessários à atuação discente no ambiente acadêmico para desenvolver habilidades de reflexão, de pesquisa e de utilização de tecnologias -, além de diversas linguagens no ensino e aprendizagem em nível de graduação. Esta metodologia é orientada pelo princípio fundamental dos métodos ativos na Educação - formulado por Piaget desde 1971, quando publicou Para Onde Vai a Educação? atendendo à Comissão Internacional para o Desenvolvimento da Educação, órgão da Unesco -, o qual ainda hoje permanece válido tanto para a educação em geral, como especialmente para a educação universitária, conforme o sentido universal que apresenta:

[...] o princípio fundamental dos métodos ativos só se pode beneficiar com a História das Ciências e assim pode ser expresso: compreender é inventar, ou reconstruir através da reinvencáa, e será preciso curvar-se ante tais necessidades se o que se pretende, para o futuro, é moldar indivíduos capazes de produzir ou de criar, e não apenas de repetir [...]. (1988, p. 17, grifos nossos).

[...] A primeira das lições a extrair das tendências interdisciplinares atuais é a necessidade de uma atenta revisião no tocante às relações futuras entre as ciências chamadas humanas e as ciências chamadas naturais $\mathrm{e}$, por conseguinte, a necessidade de se procurar um remédio para as consequências catastróficas que advieram da distribuição do ensino universitário em "Faculdades", e secundário em "seções", ambas separadas por divisões estanques [...]. (1988, p. 23, grifos nossos).

[...] Do ponto de vista pedagógico, é evidente que a Educação se deverá orientar para uma redução geral das barreiras ou para a abertura de múltiplas portas laterais a fim de possibilitar aos alunos (tanto de nível secundário quanto de nível universitário) $a$ livre transferência de uma seção para outra, com possibilidade de escolha para múltiplas combinações. Mas também será necessário, nesse caso, que se torne cada vez menos bitolado o espírito dos mestres, sendo às vezes mais difícil obter do mestre essa descentralização que do cérebro dos estudantes [...]. (1988, p. 23, grifos nossos).

Muitos autores já apontaram elementos críticos teóricos e metodológicos para a formação de geógrafos que têm largo interesse para a formação de professores de Geografia. Nesse sentido, tem sido possível mobilizar o próprio repertório que os alunos herdaram da recente formação no Ensino Médio como ponto de partida para as atividades "laboratoriais". O ponto de partida adotado, se combinado com reflexões e estudos sobre as relações que o conhecimento acadêmico e científico tem com a filosofia e o desenvolvimento das ciências humanas e naturais, estimula a aprendizagem do pensamento complexo (crítico) acerca das diversas tendências teóricas da própria Geografia para que, adiante, quando geógrafos no mundo do trabalho ou professores de geografia, os alunos possam ter mais autonomia de escolhas teóricas e metodológicas na resolução de problemas ou em seu trabalho docente.

A esse respeito, Haesbaert já considerou a necessidade de

[...] desencadear ou estimular um questionamento mais consistente sobre as bases filosóficas, nem sempre discutidas em nossos trabalhos, e sobre a chamada crise ético-social contemporânea, que tanta polêmica já gerou em outras áreas, mas que pouca repercussão teve até os anos 80 na Geografia [...]. Toda área de conhecimento que pretenda um mínimo de rigor e consistência necessita, indubitavelmente, de um domínio básico dos princípios filosóficos gerais que pautam as grandes questões humanas, colocadas e retrabalhadas, pelo menos na tradição ocidental, desde os pensadores da Grécia clássica. Ciente de sua existência e a concebendo como diferente da "natureza" ao 
seu redor, o homem tenta apreender o mundo nas suas múltiplas dimensões. Partindo de sua prática cotidiana, e sobre ela refletindo, ele começa a moldar distintas concepções do que é o mundo, até onde é possível conhecê-lo e de que modo isso pode ser feito [...]. (2006, pp. 17-18).

Outras ideias do debate teórico interno da Geografia são muito pertinentes e contribuem para se pensar e agir sobre as necessidades contemporâneas da Educação e, aqui, referimo-nos à formação de professores de Geografia para a educação básica, que precisa ser radicalmente transformada, ao invés de considerar apenas alguns aspectos imediatos e fragmentários das transformações que encontramos na realidade educacional. Milton Santos, quando problematizou a necessidade de uma Geografia Nova, afirma

[...] Quando propugnamos uma nova Geografia, isso pode, à primeira vista, parecer uma enorme pretensão, como se nos dispuséssemos a inventar o novo. A verdade, porém, é que tudo está sujeito à lei do movimento e da renovação, inclusive as ciências. $\mathrm{O}$ novo não se inventa, descobre-se... Cada vez que as condições gerais de realização da vida sobre a terra se modificam, ou a interpretação de fatos particulares concernentes à existência do homem e das coisas conhece evolução importante, todas as disciplinas científicas ficam obrigadas a realinhar-se para poder exprimir, em termos de presente e não mais de passado, aquela parcela total que lhes cabe explicar. (1978, pp. 1718, grifo nosso).

Paul Claval também se preocupou com a relevância educacional da Geografia, quando afirmou que

A Geografia explica (i) como os homens se orientam na superfície terrestre e como eles a representam; (ii) como eles a vivem, se apegam a ela e a fazem sua. Não é uma ciência natural do meio ambiente, ainda que ela integre muitos dos resultados obtidos nesse campo. É uma ecologia das sociedades humanas. O homem faz parte da natureza, como todos os outros seres, mas ele vive também no sonho, no imaginário. Suas escolhas são orientadas, seus comportamentos, justificados. Certas porções do espaço, valorizadas, até sacralizadas, em referência às imagens que ele constrói para si do alhures, do aquém ou do além... [E, ainda] Se nossas sociedades estão desamparadas, é porque a Geografia não foi ensinada como deveria ter sido: não é a ela que cabe fazer todos compreenderem como se construiu a terra dos homens e em quais condições ela pode continuar a sê-lo? (2010, pp. 133-137).

Nossa abordagem se coloca, assim, como um contraponto ao tecnicismo anti-humanista, que não tem valorizado a Geografia no quadro das Ciências Humanas para a Educação e que está presente tanto nas abordagens do ambiente acadêmico como em algumas políticas públicas. Mas este contraponto não se resume a isso. Significa também a possibilidade de reformulação das abordagens de ensino que se efetivam em ambiente do Ensino Superior e, simultaneamente, admite a necessidade de mudanças que podem ocorrer na universidade atualmente, considerando que as gerações atuais que ingressam no curso superior possuem características e exigências que refletem um mundo em constante mudança ou, como aponta Bauman (2013, p. 23), uma civilização sob o espectro do excesso, da redundância, e da superfluidez. Neste contexto, avaliamos como fundamental repensar a universidade na direção da problematização encontrada nesse autor, quando afirma que

Hoje se espera que preparemos os jovens para a vida num mundo que (na prática, mesmo que não na teoria) torna nula e vazia a própria ideia de "ser preparado" (ou seja, treinado e habilitado de forma adequada, capaz de não ser pego de surpresa por eventos e tendências cambiantes). As primeiras universidades foram fundadas no tempo em que se ergueram as catedrais góticas e destinavam-se a durar, quando não eternamente, pelo menos até o Juízo Final. Algumas dezenas de gerações depois, porém, espera-se que sua descendência realize a missão de "preparação para a vida", 
numa época em que a maioria dos arquitetos não aceitaria uma licença de construção, a menos que a ela viesse anexada uma licença de demolição dentro de vinte anos ou menos. (2014, p. 171).

Constituindo-se numa metodologia aplicada à formação inicial do geógrafo e integrada à formação do professor de Geografia, as aulas laboratoriais operam com a essência do conhecimento geográfico, articulando a singular intersecção da aprendizagem de análise de contextos e a aquisição da habilidade de filtrar as variáveis implicadas no trabalho docente e discente.

As aulas laboratoriais realizadas no início da graduação de Ensino Superior alavancam "uma atividade autêntica dos alunos, chamados a reconstruir e em parte reinventar as verdades que é preciso assimilar, e, sobretudo, uma prática individual do espírito experimental e dos métodos que o mesmo comporta" (PIAGET, 1971, p. 25), já que, ao ingressarem na Universidade, os alunos se encontram no início da passagem da cultura de massas para a cultura científica e acadêmica.

As aulas laboratoriais se organizam a partir de leituras e do exercício realizado pelos alunos de observar, identificar, comparar, analisar e explicar, oralmente e por escrito, as interfaces e aproximações possíveis e que podem ser obtidas com o entrecruzamento de sistemas teóricos que fundamentam e ilustram como funciona a aprendizagem humana segundo Piaget, Vigotski e Feuerstein, no contexto de complexidade da educação contemporânea caracterizado por Morin. Também as "figuras de homem" de Wolff (2012) fornecem elementos para resgatar o valor formativo do conhecimento acadêmico científico da Geografia, dado que tais "figuras" fazem parte da mesma história do conhecimento construído histórica e socialmente pela humanidade e que "a hiperespecialização impede de ver o global (que ela fragmenta), bem como o essencial (que ela dilui)" (MORIN, 2008).

A metodologia das aulas laboratoriais tem por objetivo prospectar ainda o alcance das interações que ocorrem em sala de aula para além do sentido tecnicista especializado e instrumental das abordagens pedagógicas que circulam nos ambientes acadêmico e educacional em geral, considerando a relevância dos temas, assuntos e conteúdos, das tecnologias, das linguagens, da mediação da aprendizagem e da valorização da dimensão histórico-cultural do ensino de graduação para a formação da cidadania.

O desenvolvimento desta metodologia consiste em organizar as atividades em grupos de alunos para estudarem e aprenderem, de modo colaborativo, as vertentes teóricas sobre como funciona a aprendizagem. E isso significa aprender conceitos e sistemas de conceitos que são relacionados e aplicados às temáticas de Geografia com a elaboração e a execução de planos de aulas no decorrer do semestre.

Os sistemas teóricos são distribuídos entre os grupos, que escolhem a temática de Geografia e elaboram o plano de aula para ministrar para a turma da disciplina Ensino de Geografia para a Educação Básica. Destacamos que os grupos são orientados conforme um cronograma de reuniões externas às aulas. Ou seja, trata-se de uma abordagem monitorada que orienta e acompanha as leituras e os estudos, estimulando o convívio, a reflexão e o trabalho acadêmico no Laboratório de Ensino e Material Didático (Lemadi) do Departamento de Geografia da USP, expandindo o sentido das aulas de graduação segundo os critérios universais de mediação de Feuerstein (1999, pp. 17-28), quais sejam: intencionalidade e reciprocidade, transcendência e significado, os quais orientam o processo da aprendizagem metacognitiva do próprio conhecimento teórico e aplicado que se pretende que o aluno alcance.

A elaboração de planos de aula supõe a dimensão técnica que qualquer planejamento requer. Entretanto, a metodologia das aulas laboratoriais é compreendida e orientada segundo a abordagem que encontramos na Teoria da Experiência de Aprendizagem Mediada de Feuerstein (FEUERSTEIN, 1999), que considera a dimensão psicológica do planejamento, especialmente, como uma das funções cognitivas subjacentes aos processos de aprendizagem e do pensar antecipado (projeção de relações virtuais) sobre possíveis dificuldades ou antecedentes da ação necessária para a realização de atividades ou solução de problemas. 
Nesta perspectiva, a atividade de elaboração de planos de aulas viabiliza a análise de dados e informações, o raciocínio lógico, o raciocínio hipotético, o raciocínio inferencial e estimula a elaboração de estratégias de ação e também de representação quando considerada a perspectiva de projeção de relações virtuais enquanto operação mental, que articula operações parcelares que integram ideias, fatos, objetos ou acontecimentos que não possuem necessariamente relação direta, mas que podem passar a se relacionar na ação, na prática.

A metodologia das aulas laboratoriais considera também a fundamentação encontrada em Vigotski (2010) a respeito da relação entre pensamento e linguagem, pois esse autor concentrou-se em trabalhos sobre a gênese interdependente dos processos de formação do pensamento e da linguagem nos indivíduos a partir da "vivência" da transmissão cultural e social em diversas escalas, desde a família e a escola, até o mundo social do trabalho.

O trabalho desse autor nos inspirou no sentido de repensar o ambiente científico e acadêmico tão significativo no início da graduação como espaço de "vivência" para os alunos. Historicamente, em nossa sociedade, a escolarização básica não tem assegurado a preparação intelectual necessária para "vivenciar" o espaço da universidade, o qual é consagrado à transmissão da alta cultura e caracterizado pela formação histórica e cultural do conhecimento e do pensamento acadêmico e científico de mais alta complexidade e abstração oriundo dos trabalhos de pesquisa. É necessário que na universidade sejam prospectadas alternativas metodológicas que apoiem e contribuam para o processo de adaptação às exigências intelectuais que caracterizam esse ambiente de aprendizagem, muito diferente do ambiente da educação básica atualmente.

As aulas laboratoriais estão organizadas em três momentos: o planejamento da prática; depois, a prática; e, em seguida, a avaliação da prática. Cada aula prevê a ocorrência dos três momentos para cada grupo, sendo que o plano de aula elaborado pelo grupo é entregue aos alunos da turma, que participam da discussão de avaliação do plano de aula feita a partir dos indicadores de avaliação, que visam a verificar em cada plano como foram construídas as articulações entre teoria e plano, teoria e prática e plano e prática. Após a realização da aula laboratorial, cada grupo elabora um Relatório circunstanciado e individual com a Metacognição do processo desenvolvido com as atividades realizadas.

De um modo geral, as aulas laboratoriais consistem na apresentação, discussão e reflexão sobre as concepções de aprendizagem, concepções de ser humano e concepções de Geografia que fundamentam a abordagem trabalhada em cada plano de aula. Trata-se de um movimento intelectual da ação para a reflexão e depois para a ação, e assim sucessivamente.

As aulas laboratoriais se configuram, portanto, como um exercício de independência intelectual e de trabalho colaborativo, que resultam em diferentes entendimentos acerca da natureza do papel do professor e do aluno na universidade, cujo movimento valoriza a vivência acadêmica do aluno e mobiliza a aprendizagem das relações entre plano-teoria-prática, favorecendo a formação de um sujeito ativo (capaz de fazer escolhas), dialógico na relação com os outros e com o próprio conhecimento, e crítico em relação às tendências que valorizam o individualismo e a efemeridade da vida social, cultural e política.

Do ponto de vista dos processos de ensino e aprendizagem, a metodologia de aulas laboratoriais propicia a formação reflexiva, condição necessária para a formação acadêmica e científica daquele que se inicia na graduação, indispensável para a formação de um pensamento crítico e argumentativo em relação a sua própria aprendizagem, podendo transferir sua auto-organização para o restante do percurso acadêmico e tirando maior proveito da relação que vai construindo com diferentes conhecimentos e com os outros, seus colegas de turma e professores.

Repensar o Ensino Superior é o único caminho, apesar das divergências e diferenças, para formar os formadores que alimentarão a utopia do humanismo, considerando a universalidade e a singularidade da humanidade, apoiando a restauração do social e do cultural para a Educação que se encontra atualmente num não lugar. 


\section{Bibliografia}

BAUMAN, Z. Sobre Educação e fuventude. Rio de Janeiro: Zahar, 2013.

\& DONSKIS, Leonidas. Cegueira Moral. Rio de Janeiro: Zahar, 2014.

CASTELLS, M. A Sociedade em Rede. São Paulo: Paz e Terra, 1999.

CLAVAL, Paul. Terra dos Homens a Geografia. São Paulo: Contexto, 2010.

FEUERSTEIN, R. Mediated Learning Experience (MLE) - Theoretical, Psychosocial and Learning Implications. London: Freund Publishing House Ltd., 1999.

HAESBAERT, Rogério. Territórios Alternativos. São Paulo: Contexto, 2006.

HARGREAVES, Andy. O Ensino na Sociedade do Conhecimento: A Educação na Era da Insegurança. Porto: Porto Editora, 2003.
MORIN, E. A Cabeça Bem-Feita: Repensar a Reforma, Reformar o Pensamento. Rio de Janeiro: Bertrand Brasil, 2008.

PIAGET, Jean. Para Onde Vai a Educação? Rio de Janeiro: José Olympio, 1988.

- Psicologia e Pedagogia: a Resposta do Grande Psicólogo aos Problemas do Ensino. Rio de Janeiro: Editora Forense Universitária, 2010.

SANTOS, Milton. Por Uma Geografia Nova: da Crítica da Geografia a uma Geografia Crítica. São Paulo: Hucitecl Edusp, 1978.

TOURAINE, A. Crítica da Modernidade. Lisboa: Instituto Piaget, 1992.

VIGOTSKI, L. S. A Construção do Pensamento e da Linguagem. São Paulo: Martins Fontes, 2010.

WOLFF, Francis. Nossa Humanidade de Aristóteles às Neurociências. São Paulo: Editora Unesp, 2012.

Publicado em 31/03/2017. 